\section{AB0856 THE IMPACT OF SYSTEMIC INFLAMMATION AND RADIOLOGICAL CHANGES ON MOBILITY IN ANCHYLOSING SPONDYLITIES}

E. Russu, L. Chislari, R. Larisa, V. Cazac. Rheumatology and Nephrology, SMPU "Nicolae Testemitanu", Chisinau, Moldova, Republic of

Objectives: The purpose of the study was to investigate the relationship between disease activity, structural lesions and physical function by testing the hypothesis that the level of structural lesions contributes independently to physical impairment.

Methods: For this analysis, the database of Rheumatology Department was used and included 78 consecutive SA patients who have been observed for many years, implying that they have used NSAID's and DMARD for progression disease, no one has used TNF blocking agents.

Results: BASFI and DFI correlated significantly ( $r$ 0.88). The correlation coefficient for mSASSS and BASFI was 0.508 and for mSASSS and DFI equal to 0.464 , suggesting a moderate correlation relationship. The correlation coefficient for the relationship between BASDAI and BASFI was equal to 0.79 and for BAS$\mathrm{DAl}$ and DFI equal to 0.69 suggesting a moderate to significant correlation. The correlation between mSASSS and BASFI or DFI was dependent on the BASDAI level.

To further investigate the relationship between mSASSS and BASFI/DFI, concurrently adjusting for BASDAl and other covariates, a multivariate analysis was performed using GEE with BASFI or DFI as dependent variables, and mSASSS and BASDAl as covariates, concurrently adjusting for age, sex, duration of illness, HLA-B27 status and hip involvement.

Both BASDAI and mSASSS contributed independently to the BASFI and DFI explanations with significant parameter estimates. Regression coefficients describe the independent relationship between the explanatory variables and the dependent variable: in the environment, compared to a patient with mSASSS 40, a patient with the mSASSS score 50 has a BASFI of 0.57 times greater, independent of BASDAI.

All mSASSS subscripts contributed independently to the explanation of BASFI variations $(p<0.001)$. Compared to the mSASSS model, which had the best result, the model with the total score of the syndesmofite, the number of the affected vertebral units, the number of vertebral vertebral units, and the model with the nonsyndesmophitary summary score, it was deduced that the syndesmophites are in much but not exclusively responsible for explaining variations in BASFI. A model with the sindesmophites summary score $(p<0.001)$ and the non-syndesmophyte $(p=0.002)$ shows that both components contribute significantly to the explanation of BASFI variations. Results with DFI were similar.

Using mSASSS, the syndesmophyte subservices, the affected vertebral units or vertebral vertebral units, we showed that lumbar and cervical spine involvement contributed independently and almost similarly to explaining variations in BASFI and DFI.

Conclusions: The study conducted by us demonstrates that the patient's physical function is not only dependent on signs and symptoms reported by the patient (activity of the disease), but also on the degree of structural lesions. Optimal AS treatment should not only include strategies aimed at removing pain, redness and fatigue, but also strategies aimed at preventing the formation and growth of syndesmofite.

Disclosure of Interest: None declared

DOI: 10.1136/annrheumdis-2018-eular.3650

\section{AB0857 THE BURDEN OF DISEASE IN PATIENTS WITH NON- RADIOGRAPHIC AXIAL SPONDYLOARTHRITIS IS NOT INFERIOR TO THAT OF ANKYLOSING SPONDYLITIS. THE PROOF STUDY}

E. de Miguel Mendieta ${ }^{1}$, S. Muñoz Fernández ${ }^{2}$, C.A. Montilla Morales ${ }^{3}$, J.M. Ruiz Martín $^{4}$, D. Reina Sanz ${ }^{5}$, C. Aguilera Cros ${ }^{6}$, M. Á. Belmonte Serrano ${ }^{7}, J$. R. Noguera Pons ${ }^{8}$, C.T. Barbazán Álvarez ${ }^{9}$, M. Arranz ${ }^{10}$, V. Díaz ${ }^{10}{ }^{1} H U$ La Paz, Madrid; ${ }^{2} \mathrm{HU}$ Infanta Sofía, Univ. Europea, San Sebastián de los Reyes; ${ }^{3} \mathrm{H}$ Clínico de Salamanca, Salamanca; ${ }^{4}$ Hospital de Viladecans, Viladecans; ${ }^{5} \mathrm{H}$ Moisés Broggi, Sant Joan Despí; ${ }^{6} \mathrm{HU}$ Virgen del Rocío, Sevilla; ${ }^{7} \mathrm{H}$ General de Castellón, Castelló de la Plana; ${ }^{8} \mathrm{HGU}$ de Elche, Elche; ${ }^{9} \mathrm{H}$ Xeral Cíes (FICHUVI), Vigo; ${ }^{10}$ AbbVie Inc., Spain, Madrid, Spain

Background: According to the 2009 ASAS classification criteria, a patient with chronic low back pain (CLBP) may be classified as axial spondyloarthritis (ax$\mathrm{SpA}$ ), with or without radiographic evidence of sacroiliitis, if at least one other SpA feature is present in the first case and positive HLA-B27 and at least two SpA features in the second one. There is concern about whether the classification "axial non-radiographic spondyloarthritis" (ax-SpA-nr) includes patients with a mild disease that do not require treatment or special care by rheumatology.
Objectives: To compare disease burden between patients fulfilling criteria for AS and ax-SpA-nr.

Methods: Sub-analysis of Spanish patients from the PROOF study, an international prospective observational longitudinal study conducted in rheumatology clinics. All patients who attended rheumatology clinics due to CLBP ( $\geq 3$ months, start $<45$ years of age) from ${ }^{\mathrm{Jan}} 2015$ to ${ }^{\text {Feb }} 2017$ not previously diagnosed were consecutively included. The ASAS criteria were applied to all, with centralised image reading. Patients with AS and ax-SpA-nr were compared.

Results: 192 patients with CLBP were included, of whom 151 (79\%) met criteria of SpA-axe, $56(43 \%)$ of AS and $74(57 \%)$ of ax-SpA-nr (21 patients had X-ray missing or no central reading had been done so far). The table shows the description of patients with $\mathrm{AS}$ and $\mathrm{ax}-\mathrm{SpA}$-nr and their comparison.

Abstract AB0857 - Table 1

\begin{tabular}{|c|c|c|c|}
\hline Characteristic & $\begin{array}{r}\text { AS } \\
(n=56)\end{array}$ & $\begin{array}{r}\text { ax-SpA-nr } \\
(n=74)\end{array}$ & $\mathbf{p}$ \\
\hline Age, $\mathrm{m}(\mathrm{SD})$ & $33.8(8.0)$ & $36.2(8.6)$ & 0.117 \\
\hline Men, $\mathrm{n}(\%)$ & $41(73.2)$ & $39(52.7)$ & 0.019 \\
\hline HLA-B27 positive, n (\%) & $37(66.1)$ & $44(61.1)$ & 0.585 \\
\hline BASDAI, m (SD) & $3.9(2.4)$ & $4.3(2.3)$ & 0.397 \\
\hline ASDAS-CRP, $\mathrm{m}$ (SD) & $2.8(1.2)$ & $2.6(1.1)$ & 0.224 \\
\hline C-reactive Protein (mg/L), m (SD) & $13.9(15.0)$ & $10.3(19.9)$ & 0.264 \\
\hline Erythrocyte sedimentation rate $(\mathrm{mm} / \mathrm{h}), \mathrm{m}$ (SD) & $18.0(19.1)$ & $13.6(17.5)$ & 0.208 \\
\hline BASFI, m (SD) & $3.0(2.5)$ & $3.1(2.4)$ & 0.828 \\
\hline SF-12 (physical component), m (SD) & $44.1(10.7)$ & $42.2(9.2)$ & 0.283 \\
\hline SF-12 (mental component), m (SD) & $46.9(10.0)$ & $43.1(10.5)$ & 0.040 \\
\hline \multicolumn{4}{|l|}{ Items from WPAI-SHP } \\
\hline Active (employed), $\mathrm{n}(\%)$ & $39(69.6)$ & $54(74.0)$ & 0.693 \\
\hline Presentism, $\mathrm{m}(\mathrm{SD})^{*}$ & $26.2(25.6)$ & $33.9(29.8)$ & 0.206 \\
\hline Absenteeism, $\mathrm{m}(\mathrm{SD})^{*}$ & $2.4(6.9)$ & $11.2(28.2)$ & 0.041 \\
\hline Impact of work productivity, m (SD)* & $27.0(27.5)$ & $34.0(29.6)$ & 0.280 \\
\hline Total impact on work activity, $\mathrm{m}(\mathrm{SD})^{*}$ & $34.2(29.8)$ & $41.0(30.2)$ & 0.209 \\
\hline Smokers, n (\%) & 24 (43.6) & $19(26.0)$ & 0.040 \\
\hline $\begin{array}{l}\text { Time in months from pain onset until } 1^{\text {st }} \text { study } \\
\text { visit, } m \text { (SD) }\end{array}$ & $37.5(42.9)$ & $43.3(56.1)$ & 0.509 \\
\hline \multicolumn{4}{|l|}{ Treatments used in the study visit, $\mathrm{n}(\%)$} \\
\hline Non-steroidal anti-inflammatory drugs & 24 (42.9) & $24(32.4)$ & 0.223 \\
\hline Methotrexate & $1(1.8)$ & $1(1.4)$ & 1.000 \\
\hline Sulfasalazine & $1(1.8)$ & $3(4.1)$ & 0.634 \\
\hline Glucocorticoids & $8(14.3)$ & $8(10.8)$ & 0.550 \\
\hline Analgesics & $7(12.5)$ & $13(17.6)$ & 0.428 \\
\hline TNF inhibitors & 0 & $1(1.4)$ & \\
\hline
\end{tabular}

*Only among actively employed.

Abbreviations: m, mean; SD, standard deviation; BASDAI, Bath Ankylosing Spondylitis Disease Activity Score; ASDAS-CRP, Ankylosing Spondylitis Disease Activity Score calculated with C-reactive protein; BASFI, Bath Ankylosing Spondylitis Functional Index; SF-12, Short Form questionnaire, 12 items version; WPAI-SHP, Work Productivity and Activity Impairment Questionnaire related to disease; TNF, tumour necrosis factor.

Conclusions: Patients referred by CLBP to rheumatology clinics meeting ASAS criteria for AS or ax-SpA-nr differ little in terms of impact and disease activity; therefore, non-radiographic forms of ax-SpA require as much attention as classic AS.

Acknowledgements: The PROOF study was sponsored by AbbVie. AbbVie contributed to the study design, research, and interpretation of data, writing, reviewing, and approving the publication. The authors wish to thank Loreto Carmona (InMusc) for providing medical writing and editing services in the development of this abstract. The financial support for these services was provided by AbbVie.

Disclosure of Interest: E. de Miguel Mendieta Grant/research support from Abbvie, S. Muñoz Fernández Grant/research support from: Abbvie, C. Montilla Morales Grant/research support from: Abbvie, J. Ruiz Martín Grant/research support from: Abbvie, D. Reina Sanz Grant/research support from: Abbvie, C. Aguilera Cros Grant/research support from: Abbvie, M. Á. Belmonte Serrano Grant/ research support from: Abbvie, J. R. Noguera Pons Grant/research support from: Abbvie, C. Barbazán Álvarez Grant/research support from: Abbvie, M. Arranz Employee of: Abbvie, V. Díaz Employee of: Abbvie DOI: 10.1136/annrheumdis-2018-eular.1395

\begin{tabular}{|l|l|}
\hline AB0858 & IMPACT OF APPLICATION OF ASAS CRITERIA FOR \\
AXIAL SPONDYLOARTHRITIS ON THE DIAGNOSTIC \\
DELAY IN EGYPTIAN PATIENTS
\end{tabular}

F.I. Abdelrahman, M. Mortada. Rheumatology, ZAGAZIG UNIVERSITY, zagazig, Egypt

Background: Diagnostic delay is a major challenge in axial spondyloarthritis (SpA). The 2009 Assessment of SpondyloArthritis international Society 
classification(ASAS) criteria for axial SpA formally recognised the utility of MRI in diagnosis. ${ }^{1}$ There are conflicting reports whether there had been any recent improvement in the period of diagnostic delay after application of ASAS criteria. ${ }^{2}$ Objectives: To evaluate the period from symptoms onset to diagnosis in Egyptian patients with axial SpA before and after application of ASAS criteria for axial $\mathrm{SpA}$ and to examine possible reasons for delayed diagnosis.

Methods: The study included all axial SpA patients attending a university tertiary referral centre for regular follow up in the period between May 2016 to November 2017. The patients were divided into 2 groups; group 1 included patients with a diagnosis of axial SpA before the beginning of 2010 (when ASAS criteria became widely available and in use) and group 2 included patients with a diagnosis of axial SpA after the beginning of 2010. A face-to-face interview was applied for both groups to take medical history, and a questionnaire that contains some clinical aspects of disease was used. Diagnosis delay was described as the gap between first SpA symptom and correct diagnosis of axial SpA. Clinical and functional assessment of axial SpA measured by Bath Ankylosing Spondylitis Disease Activity Index (BASDAI), Bath Ankylosing Spondylitis Functional Index (BASFI), Bath Ankylosing Spondylitis Metrology Index (BASMI). The direct medical cost during years of delay (including costs of medical consultations, medications, investigations, physiotherapy and surgical treatment) had been estimated.

Results: As presented in table 1; more axial SpA cases were in group 2 (diagnosed after the beginning of 2010) with significantly narrower gap of delay, younger age at diagnosis, lesser number of doctor visits, lesser number of unnecessary spinal surgeries, lower total direct estimated costs and better BASDI, BASFI and BASMI.

Abstract AB0858 - Table 1. comparison between axial SpA patients diagnosed before and after 2010

\begin{tabular}{|c|c|c|c|}
\hline Variable & $\begin{array}{c}\text { Group } 1 \\
(\mathrm{n}=56)(44.4 \%)\end{array}$ & $\begin{array}{c}\text { Group } 2 \\
(n=70) \\
(55.6 \%)\end{array}$ & $\mathrm{p}$-value \\
\hline $\begin{array}{l}\text { Delay in years: } \\
\text { Mean } \pm S D\end{array}$ & $11.3 \pm 3.9$ & $4.6 \pm 2.8$ & $0.02^{\star \star}$ \\
\hline $\begin{array}{l}\text { Sex: } \\
\text { Male: } \\
\text { Female: }\end{array}$ & $\begin{array}{l}49(83.3) \\
7(16.7)\end{array}$ & $\begin{array}{c}56(7.9) \\
14(92.1)\end{array}$ & $0.3^{*}$ \\
\hline $\begin{array}{l}\text { Age at diagnosis (years): } \\
\text { Mean } \pm S D\end{array}$ & $34.9 \pm 6.4$ & $25.8 \pm 4.5$ & $0.03^{\star \star}$ \\
\hline $\begin{array}{l}\text { Cost of delay period by } \$ \text { : } \\
\text { Mean } \pm S D\end{array}$ & $\begin{array}{c}9879.3 \\
\pm 3827.2\end{array}$ & $2373.9 \pm 881.8$ & $<0.001^{\star *}$ \\
\hline $\begin{array}{l}\text { Doctor Visits during years of } \\
\text { delay: } \\
\text { Mean } \pm S D\end{array}$ & $14.3 \pm 6$ & $5.6 \pm 3.4$ & $<0.001^{\star *}$ \\
\hline $\begin{array}{l}\text { Spinal Surgery: } \\
\text { Loss of work at time of diagnosis: }\end{array}$ & $\begin{array}{c}34(65.4 \%) \\
36\end{array}$ & $\begin{array}{c}18(34.6 \%) \\
7\end{array}$ & $\begin{array}{l}<0.001^{*} \\
<0.001^{*}\end{array}$ \\
\hline $\begin{array}{l}\text { BASDAI: } \\
\text { Mean } \pm S D\end{array}$ & $9.1 \pm 1.4$ & $4.3 \pm 2.2$ & $<0.001^{* *}$ \\
\hline $\begin{array}{l}\text { BASFI: } \\
\text { Mean } \pm S D\end{array}$ & $9.1 \pm 1.4$ & $3.9 \pm 2.2$ & $<0.001^{\star *}$ \\
\hline $\begin{array}{l}\text { BASMI: } \\
\text { Mean } \pm S D\end{array}$ & $8.9 \pm 1.2$ & $2.2 \pm 2$ & $<0.001^{\star \star}$ \\
\hline
\end{tabular}

*: Chi-square test. SD: Standard Deviation. **: Independent sample t test.

Significance $p$ value $<0.05$.

Conclusions: Application of ASAS criteria for axial SpA has resulted in a significant decrease in the diagnostic gap which is reflected in a significant decrease in age at diagnosis and in the costs of unnecessary medications. On the other side, the gap is still large and more sensitive criteria are still needed.

\section{REFERENCES:}

[1] Rudwaleit M. et al: The development of Assessment of Spondyloarthritis international Society classification criteria for axial spondyloarthritis; Ann Rheum Dis, 68 (2009), pp.777-783.

[2] Sykes M. et al: Diagnostic delay in patients with rheumatoid arthritis, psoriatic arthritis and ankylosing spondylitis; Ann Rheum Dis.2015;74:e44.

Disclosure of Interest: None declared

DOI: 10.1136/annrheumdis-2018-eular.6965

\section{AB0859 \\ SIMILARITIES AND DIFFERENCES BETWEEN NON- RADIOGRAPHIC AND RADIOGRAPHIC AXIAL} SPONDYLOARTHRITIS IN PROOF CHINA COHORT

F. Huang ${ }^{1}$, C. Bao ${ }^{2}$, Y. Fang ${ }^{3}$, L. Wu ${ }^{4}$, L. Jiang ${ }^{5}$, D. He ${ }^{6}$, J. Xu ${ }^{7}$, F. Zhang ${ }^{8}$, X. Zhang ${ }^{9}$, L. Bi ${ }^{10}$, M. Hojnik ${ }^{11}$, D. Poddubnyy ${ }^{12} .{ }^{1}$ Chinese PLA General Hospital, Beijing; ${ }^{2}$ Renji Hospital of Shanghai Jiao Tong University School of Medicine, Shanghai; ${ }^{3}$ Southwest Hospital, Third Military Medical University, Chongqing; ${ }^{4}$ People's Hospital of Xinjiang Uygur Autonomous Region, Urumqi; ${ }^{5}$ Zhongshan Hospital affiliated with Fudan University; ${ }^{6}$ Guanghua Integrative Medicine Hospital, Shanghai; ${ }^{7}$ First Affiliated Hospital of Anhui Medical University, Hefei; ${ }^{8}$ Peking Union Medical College Hospital, Beijing; ${ }^{9}$ Guangdong General Hospital and Guangdong Academy of Medical Sciences, Guangzhou; ${ }^{10} \mathrm{China}$-Japan Union Hospital of Jilin University, Changchun, China; ${ }^{11}$ AbbVie, Ljubljana, Slovenia; ${ }^{12}$ Charité Universitätsmedizin Berlin, Berlin, Germany

Background: National observational studies, mostly from Europe, have reported some differences between radiographic axial spondyloarthritis (axSpA) and nonradiographic axSpA (nr-axSpA).

Objectives: To compare demographic and clinical characteristics of patients (pts) with nr-axSpA and radiographic axSpA (ankylosing spondylitis, AS) in a Chinese subpopulation in the PROOF study.

Methods: PROOF is a prospective observational study evaluating clinical and radiographic outcomes in axSpA pts in rheumatology clinical practice in 29 countries over 5 years. Pts diagnosed $\leq 1$ year before study enrollment with axSpA fulfilling ASAS classification criteria were eligible. Investigator confidence with the axSpA diagnosis was ascertained on a numeric rating scale $(0-10)$ at enrollment and end of follow-up. Baseline characteristics are reported, including demographics and clinical characteristics (table 1). Classification as nr-axSpA or AS was according to the radiologic criterion of the modified New York criteria. If there was a disagreement in classification ( $\mathrm{nr}-\mathrm{axSpA}$ or AS) between a local and central reader, the radiograph was evaluated by a second central reader, who was blinded to previous assessments; the final classification was based on the decision of 2 of 3 readers.

Results: 464 (21.8\%) pts in PROOF were enrolled in China; 307 (66.2\%) were classified as AS and $157(33.8 \%)$ as $\mathrm{nr}$-axSpA according to the investigators Confidence with the axSpA diagnosis was 9.0 1.5 . The final classification based on central assessment of sacroiliac radiographs was confirmed in $372(80 \%)$ pts included in further analyses; 301 pts $(80.9 \%)$ were classified as AS and 71 $(19.1 \%)$ as nr-axSpA. AS pts had longer time since diagnosis, more frequent and higher CRP elevations, and were more often male and treated with TNF inhibitors (table 1). HLA-B27 positivity and prevalence of other SpA features were comparable between the 2 groups. Most disease burden assessments were comparable, but ASDAS-CRP, BASFI, and SF-12v2 physical component score were higher in AS pts (table 1)

Abstract AB0859 - Table 1. Baseline Demographics and Clinical Characteristic of the Chinese PROOF Subpopulation

\begin{tabular}{|c|c|c|c|c|}
\hline \multicolumn{2}{|c|}{ Characteristic } & $\begin{array}{c}\text { nr-axSpA } \\
(n=71)\end{array}$ & $\underset{(n=301)}{\substack{\text { AS } \\
\text { (n) }}}$ & $P$ Value $^{\mathrm{a}}$ \\
\hline \multicolumn{2}{|c|}{ Age, $y$, mean $\pm S D$} & $30.1 \pm 8.9$ & $29.4 \pm 8.7$ & 0.517 \\
\hline \multicolumn{2}{|c|}{ Time since back pain onset, $m o$, mean $\pm S D$} & $28.9 \pm 47.1$ & $36.8 \pm 50$ & 0.216 \\
\hline \multicolumn{2}{|c|}{ Time since diagnosis, $m 0$, mean $\pm \mathrm{SD}$} & $1.7 \pm 2.1$ & $2.8 \pm 3.5$ & $0.005^{\star}$ \\
\hline \multicolumn{2}{|c|}{ Male sex, $n(\%)$} & $40(56.3)$ & $239(79.4)$ & $<0.001^{\star *}$ \\
\hline \multirow{12}{*}{$\begin{array}{l}\text { Number of po } \\
\text { SpA } \\
\text { parameters, } \\
n(\%)\end{array}$} & itive SPA parameters, mean \pm SD & $3.5 \pm 1.1$ & $3.6 \pm 1.3$ & 0.508 \\
\hline & HLA-B27+ & $54(77.1)$ & $237(81.2)$ & 0.503 \\
\hline & Inflammatory back pain & $68(95.8)$ & $291(96.7)$ & 0.720 \\
\hline & Peripheral arthritis & $21(29.6)$ & $97(32.2)$ & 0.777 \\
\hline & Enthesitis (heel) & $22(31.0)$ & $62(20.6)$ & 0.082 \\
\hline & Dactylitis & $3(4.2)$ & $10(3.3)$ & 0.720 \\
\hline & Uveitis & $4(5.6)$ & $18(6.0)$ & 1.000 \\
\hline & Psoriasis & 0 & $2(0.7)$ & 1.000 \\
\hline & IBD & 0 & 0 & - \\
\hline & Good response to NSAIDs & $44(62.0)$ & $175(58.1)$ & 0.556 \\
\hline & Family history of SpA & $13(18.3)$ & $45(15.0)$ & 0.471 \\
\hline & Elevated CRP, $n(\%)$ & $22(31.0)$ & $157(52.2)$ & $0.002^{\star}$ \\
\hline \multirow{8}{*}{$\begin{array}{l}\text { Disease } \\
\text { activity } / \\
\text { PRO } \\
\text { measures, } \\
\text { mean } \pm \text { SD }\end{array}$} & CRP, $\mathrm{mg} / \mathrm{L}$ & $10.2 \pm 20.4$ & $16.5 \pm 21.4$ & $0.033^{\star}$ \\
\hline & ASDAS-CRP & $2.2 \pm 1.0$ & $2.6 \pm 1.0$ & $0.013^{\star}$ \\
\hline & BASDAI, NRS $(0-10)$ & $3.3 \pm 1.9$ & $4.3 \pm 1.9$ & 0.946 \\
\hline & Patient global, NRS $(0-10)$ & $3.7 \pm 2.4$ & $3.9 \pm 2.3$ & 0.628 \\
\hline & BASFI, NRS $(0-10)$ & $1.3 \pm 1.4$ & $1.9 \pm 1.8$ & $0.002^{\star}$ \\
\hline & SF-12ㄴ PCS & $45.2 \pm 6.6$ & $42.1 \pm 8.2$ & $0.001^{*}$ \\
\hline & SF-12V 2 MCS & $44.3 \pm 9.7$ & $45.4 \pm 9.4$ & 0.358 \\
\hline & WPAI-SHP TAI & $31.7 \pm 20.6$ & $34.7 \pm 23.8$ & 0.289 \\
\hline \multirow{6}{*}{$\begin{array}{l}\text { Current } \\
\text { treatment, } \\
\mathrm{n}(\%)\end{array}$} & NSAID & $55(77.5)$ & $213(70.8)$ & 0.304 \\
\hline & Methotrexate & $3(4.2)$ & $19(6.3)$ & 0.779 \\
\hline & Sulfasalazine & $27(38.0)$ & $88(29.2)$ & 0.156 \\
\hline & Steroids & $1(1.4)$ & $4(1.3)^{\prime}$ & 1.000 \\
\hline & Analgesics & $1(1.4)$ & $4(1.3)$ & 1.000 \\
\hline & TNF-a inhibitors & $8(11.3)$ & $79(26.3)$ & $0.008^{* *}$ \\
\hline
\end{tabular}

AS=ankylosing spondylitis; ASDAS-CRP=AS Disease Activity Score containing C-reactive protein; BASDAl=Bath Ankylosing Spondylitis Disease Activity Index $\mathrm{BASFI}=$ Bath Ankylosing Spondylitis Functional Index; $\mathrm{CRP}=\mathrm{C}$ reactive protein HLA-B27=human leukocyte antigen B27; MCS=Mental Component Summary; nr-axSpA=non radiographic axial spondyloarthritis; NSAID=non steroidal antiinflammatory drug; PCS=Physical Component Summary; SF-12v2=Short Form 12-item Health Survey version 2; TNF=tumour necrosis factor; WPAI-SHP TAI=Work Productivity and Activity Impairment Questionnaire-Specific Health 